\title{
Characterization of Aroma Active Compounds in Fruit Juice and Peel Oil of Jinchen Sweet Orange Fruit (Citrus sinensis (L.) Osbeck) by GC-MS and GC-O
}

\author{
Yu Qiao, Bi Jun Xie, Yan Zhang, Yun Zhang, Gang Fan, Xiao Lin Yao and Si Yi Pan * \\ College of Food Science and Technologhy, Huazhong Agricultural University, Shizhishan Street No. \\ 1, Wuhan, Hubei, 430070, P. R. China \\ * Author to whom correspondence should be addressed; E-mail: pansiyi@mail.hzau.edu.cn
}

Received: 20 April 2008; in revised form: 19 May 2008/Accepted: 19 May 2008 / Published: 12 June 2008

\begin{abstract}
Gas chromatography-mass spectrometry (GC-MS) and gas chromatographyolfactometry (GC-O) were used to determine the aromatic composition and aroma active compounds of fruit juice and peel oil of Jinchen sweet orange fruit. Totals of 49 and 32 compounds were identified in fruit juice and peel oil, respectively. GC-O was performed to study the aromatic profile of Jinchen fruit juice and peel oil. A total of 41 components appeared to contribute to the aroma of fruit juice and peel oil. Twelve components were the odorants perceived in both samples. The aromatic compositions of fruit juice were more complex than that of peel oil. Ethyl butanoate, $\beta$-myrcene, octanal, linalool, $\alpha$-pinene, and decanal were found to be responsible for the aromatic notes in fruit juice and peel oil. Nineteen components have been perceived only in the juice and ten compounds were described as aromatic components of only the peel oil by the panelists. These differences lead to the different overall aroma between fruit juice and peel oil.
\end{abstract}

Keywords: Aroma, GC-MS, GC-O, Jinchen, fruit juice, peel oil

\section{Introduction}

Orange fruits are the most popular ones for consumers throughout the world due to their pleasant flavors and nutritional value [1]. The fruits are both consumed fresh and industrially processed. The 
pulps, which are rich in soluble sugars, significant amounts of vitamin $\mathrm{C}$, pectin, fiber and different organic acids, are mainly used to process into juice. Orange peels containing abundant fragrant substances are extensively applied for processing into essential oils which are used commercially for flavoring foods, beverages, perfumes, cosmetics, etc.

Analytical research on the aroma compounds in orange fruit has been carried out for many years. Many researchers have studied the volatile compounds of this fruit using different analytical methods [2-7]. As a result of these studies, more than 200 components have been described as components of the flavor of sweet orange, and the major aroma compounds found in orange juice are hydrocarbons, alcohols, aldehydes, esters, and ketones. The presences of terpenes with traces of oxygenated components are the aromatic character in the orange essential oil and peel oil [8-13].

Only a small part of all volatiles present in food has a primary impact on aroma [14]. The aromatic quality of the fruit is primarily dependent on the aroma active compounds. Gas chromatographyolfactometry (GC-O) analysis is a valuable method for the detection of aroma active compounds from a food matrix [15-17]. The three main GC-O methods are the dilution analysis, detection frequency and perceived intensity method [18-19], and these techniques have been employed by various researchers to determine the aroma impacting compounds in orange juice [20-23]. Solid phase microextraction (SPME) is a rapid, solvent-free, low-cost, simple extracting method [24-25], and usually combined with GC-O analysis. The amounts of flavor compounds absorbed on the SPME coating were greatly influenced by the diffusion of flavor components through orange juice into the headspace and the headspace gas reach to the SPME coating. Therefore, the high correlations between the concentrations and GC peak area were not obtained for all the volatile compounds [26]. It is also difficult to perform the dilution analysis such as AEDA using SPME extracts. Kim et al. varied the GC injector split ratio to achieve dilution stepwise of the flavor compounds in HS-SPME-GC-O using an aqueous model system and yuzu tea. The research only demonstrated that serial dilution of the four flavor compounds in yuzu can be achieved successful through the increase of GC split ratio, other aroma compounds was not be mentioned [27]. Some researchers conducted the intensity method or frequency method combined with SPME to analysis orange juice flavor. Bazeome et al. stated that ethyl butanoate, mycrene, trans-2-nonenal, decanal, octanal, terpinen-4-ol, cis-hex-3-enal and three unkown compounds were aroma active compounds in unpasteurized juice and heated juice, using SPME extraction and intensity method [20]. Arena et al. used frequency detection method and SPME to find twenty-two odor active compounds in hand-squeezed juices of Moro, Tarocco, Washington navel and Valencia late oranges [23].

$\mathrm{GC}-\mathrm{O}$ procedure has also been conducted to characterize the aroma active components in some citrus essential oils. Lin and Rouseff detected 38 aroma-active compounds in commercial cold-pressed grapefruit oil using a time-intensity $\mathrm{GC}-\mathrm{O}$ procedure and concluded that the greatest aroma intensity compounds were1, 8-cineole, octanal, dodecanal, trans-4,5-epoxy-(E)-2-decenal, $\beta$-sinensal and nootkatone [28]. Högnadóttir and Rouseff found 55 aroma active compounds of the detected 95 volatile compounds in orange essence oil. The flavor compounds in orange peel oil extracted by SPME have never been reported [11].

Jinchen is a native sweet crop of Citrus Sinensis. It originated from the Sichuan province and has been widely planted in the middle and upper regions of the Yangtze River. No research on Jinchen aroma has ever been reported, though Jinchen is of economic importance to the citrus industry in 
China. The aim of the study was to determine the aroma active compounds in Jinchen orange fruit juice and peel oil by GC-MS and GC-O, as well as to provide useful information about the most important potent odorants in this fruit.

\section{Results and Discussion}

Volatile components in fresh Jinchen fruit juice and peel oil

In the analysis of volatile components present in Jinchen fruit juice, a total of 49 compounds were identified including 20 hydrocarbons, 10 aldehydes, nine esters, nine alcohols, and one ketone (Table 1). Limonene, followed by linalool, terpinen-4-ol, $\beta$-myrcene, $\alpha$-terpineol, octanal, and $\gamma$-terpinene were the components found in greatest proportions.

Table 1. Volatile components identified in fruit juice and peel oil of Jinchen fruit by GC-MS.

\begin{tabular}{|c|c|c|c|c|c|}
\hline \multirow{2}{*}{$\begin{array}{c}\text { RI } \\
(\mathbf{H P}-5)\end{array}$} & \multirow{2}{*}{ RIL } & \multirow{2}{*}{ Compound name } & \multicolumn{2}{|c|}{ Peak area $(\%) \pm S D$} & \multirow{2}{*}{ Identification } \\
\hline & & & Fruit juice & Peel oil & \\
\hline 600 & 613 [29] & Ethyl acetate & $0.02 \pm 0.00$ & n.d. & MS, RT \\
\hline 710 & 712 [29] & Ethyl propanoate & $0.01 \pm 0.01$ & n.d. & MS, RI \\
\hline 725 & $724[29]$ & Methyl butanoate & trace & n.d. & MS, RI \\
\hline 794 & 806 [29] & Hexanal & $0.07 \pm 0.06$ & n.d. & MS, RT \\
\hline 796 & $800[11]$ & Ethyl butanoate & $0.24 \pm 0.03$ & n.d. & MS, RT \\
\hline 847 & $848[11]$ & trans-2-Hexenal & $0.05 \pm 0.00$ & n.d. & MS, RT \\
\hline 900 & $910[29]$ & Heptanal & trace & n.d. & MS, RI \\
\hline 924 & $923[30]$ & $\alpha$-Thujene & $0.03 \pm 0.02$ & $0.04 \pm 0.00$ & MS, RI \\
\hline 930 & $934[11]$ & $\alpha$-Pinene & $0.61 \pm 0.10$ & $0.76 \pm 0.02$ & MS, RT \\
\hline 958 & 968 [29] & Benzaldehyde & $0.04 \pm 0.01$ & n.d. & MS, RT \\
\hline 971 & $974[11]$ & Sabinene & $0.02 \pm 0.01$ & $0.49 \pm 0.01$ & MS, RI \\
\hline 973 & $990[11]$ & $\beta$-Pinene & $0.07 \pm 0.01$ & n.d. & MS, RI \\
\hline 991 & $994[11]$ & $\beta$-Myrcene & $2.38 \pm 0.33$ & $1.88 \pm 0.04$ & MS, RT \\
\hline 1004 & $1005[15]$ & Octanal & $1.36 \pm 0.13$ & $0.34 \pm 0.09$ & MS, RT \\
\hline 1010 & $1012[11]$ & $\delta$-3-Carene & n.d. & $0.14 \pm 0.07$ & MS, RI \\
\hline 1007 & $1039[15]$ & Limonene & $77.8 \pm 4.86$ & $90.85 \pm 0.11$ & MS, RT \\
\hline 1053 & $1036[10]$ & cis- $\beta$-Ocimene & $0.28 \pm 0.02$ & $0.26 \pm 0.03$ & MS, RI \\
\hline 1063 & $1074[11]$ & $\gamma$-Terpinene & $0.92 \pm 0.23$ & $1.21 \pm 0.03$ & MS, RI \\
\hline 1074 & $1074[11]$ & 1-Octanol & $0.04 \pm 0.02$ & n.d. & MS, RT \\
\hline 1089 & $1096[11]$ & Terpinolene & $0.18 \pm 0.02$ & $0.08 \pm 0.00$ & MS, RI \\
\hline 1104 & $1107[11]$ & Linalool & $3.9 \pm 0.82$ & $0.92 \pm 0.02$ & MS, RT \\
\hline 1106 & $1109[11]$ & Nonanal & n.d. & $0.08 \pm 0.01$ & MS, RT \\
\hline 1133 & $1133[29]$ & $\begin{array}{l}\text { Ethyl 3-hydroxy- } \\
\text { hexanoate }\end{array}$ & $0.08 \pm 0.01$ & n.d. & MS, RI \\
\hline 1135 & & $\begin{array}{l}( \pm) \text {-4-Acetyl-1-methyl- } \\
\text { cyclohexene }\end{array}$ & $0.03 \pm 0.01$ & n.d. & MS \\
\hline 1139 & $1147[11]$ & trans-Limonene oxide & n.d. & $0.01 \pm 0.00$ & MS, RI \\
\hline 1149 & 1159 [11] & $\beta$-Terpineol & $0.15 \pm 0.11$ & n.d. & MS, RI \\
\hline
\end{tabular}




\begin{tabular}{|c|c|c|c|c|c|}
\hline 1159 & 1159 [11] & Citronellal & n.d. & $0.06 \pm 0.00$ & MS, RI \\
\hline 1185 & 1179 [15] & Terpinen-4-ol & $3.06 \pm 0.80$ & n.d. & MS, RI \\
\hline 1199 & $1207[11]$ & $\alpha$-Terpineol & $1.61 \pm 0.45$ & $0.07 \pm 0.01$ & MS, RT \\
\hline 1208 & $1208[15]$ & Decanal & $0.51 \pm 0.05$ & $0.21 \pm 0.01$ & MS, RT \\
\hline 1223 & $1229[11]$ & trans-Carveol & $0.1 \pm 0.03$ & n.d. & MS, RI \\
\hline 1232 & $1237[31]$ & Nerol & $0.19 \pm 0.16$ & n.d. & MS, RI \\
\hline 1244 & 1248 [29] & Neral & $0.02 \pm 0.00$ & $0.06 \pm 0.02$ & MS, RT \\
\hline 1247 & $1256[11]$ & Carvone & $0.14 \pm 0.04$ & n.d. & MS, RI \\
\hline 1258 & $1252[11]$ & Geraniol & $0.04 \pm 0.01$ & n.d. & MS, RI \\
\hline 1273 & 1280 [29] & Geranial & $0.03 \pm 0.01$ & $0.11 \pm 0.03$ & MS, RT \\
\hline 1277 & $1290[11]$ & Perillaldehyde & $0.33 \pm 0.11$ & $0.03 \pm 0.00$ & MS, RI \\
\hline 1295 & 1303 [29] & Thymol & $0.03 \pm 0.01$ & trace & MS, RI \\
\hline 1307 & 1314 [29] & Undecanal & $0.02 \pm 0.00$ & n.d. & MS, RI \\
\hline 1338 & & cis-Carveyl acetate & trace & n.d. & MS \\
\hline 1350 & $1347[11]$ & $\alpha$-Cubebene & $0.02 \pm 0.00$ & n.d. & MS, RI \\
\hline 1354 & $1348[11]$ & Citronellyl acetate & $0.02 \pm 0.00$ & $0.01 \pm 0.00$ & MS, RT \\
\hline 1365 & $1376[11]$ & Neryl acetate & $0.04 \pm 0.01$ & $0.02 \pm 0.00$ & MS, RT \\
\hline 1377 & 1380 [29] & $\alpha$-Copaene & $0.05 \pm 0.01$ & $0.04 \pm 0.00$ & MS, RI \\
\hline 1384 & 1385 [29] & Geranyl acetate & $0.03 \pm 0.01$ & trace & MS, RT \\
\hline 1391 & $1390[30]$ & $\beta$-Cubebene & $0.01 \pm 0.00$ & $0.03 \pm 0.01$ & MS, RI \\
\hline 1393 & $1393[30]$ & $\beta$-Elemene & $0.02 \pm 0.00$ & n.d. & MS, RI \\
\hline 1417 & $1411[11]$ & Dodecanal & n.d. & $0.03 \pm 0.01$ & MS, RI \\
\hline 1412 & $1427[30]$ & $\beta$-Gurjurene & n.d. & $0.01 \pm 0.00$ & MS, RI \\
\hline 1450 & $1456[30]$ & Alloaromadendrene & trace & n.d. & MS, RI \\
\hline 1455 & $1454[30]$ & $\alpha$-Caryophyllene & $0.01 \pm 0.00$ & n.d. & MS, RI \\
\hline 1482 & 1490 [29] & Germacrene D & $0.02 \pm 0.01$ & $0.08 \pm 0.01$ & MS, RI \\
\hline 1485 & & $\begin{array}{l}\text { 2-Isopropenyl-4a,8- } \\
\text { dimethyl-1,2,3,4,4a, } \\
\text { 5,6,7- } \\
\text { octahydronaphthalene }\end{array}$ & $0.02 \pm 0.00$ & n.d. & MS \\
\hline 1495 & 1498 [29] & Valencene & $0.38 \pm 0.03$ & $0.05 \pm 0.01$ & MS,RT \\
\hline 1499 & $1491[31]$ & Bicyclogermacrene & n.d. & trace & MS,RI \\
\hline 1525 & & $\delta$-Amorphene & $0.09 \pm 0.01$ & $0.05 \pm 0.01$ & MS \\
\hline \multirow[t]{2}{*}{1812} & $1833[11]$ & Nootkatone & $0.02 \pm 0.01$ & $0.01 \pm 0.00$ & MS,RI \\
\hline & & Total & $95.05 \pm 8.43$ & $97.94 \pm 0.55$ & \\
\hline
\end{tabular}

RT: identified by retention time of standard compounds

RI: identified by retention index and compared with those reported in the literature MS: confirmed by mass spectrum n.d.: not detected

In peel oil extracts, a total of 32 compounds were identified in the volatile fraction, including 16 hydrocarbons and eight aldehydes, three esters, three alcohols, one ketone and one terpenic oxide (Table 1). Among these components, limonene was the one found in greatest concentrations, representing $90.85 \%$ of all volatiles. Other predominant components were $\beta$-myrcene, $\gamma$-terpinene, linalool and $\alpha$-pinene. 
In both samples the major compounds were monoterpenes and sesquiterpenes. The peel oil contained terpenes at higher levels than those of the fruit juice, except for cis- $\beta$-ocimene, $\beta$-myrcene, terpinolene, $\delta$-amorphene and valencene. Three sesquiterpenes which could not be found in peel oil were detected in small quantity in fruit juice: $\alpha$-cubebene, $\beta$-elemene, and $\alpha$-caryophyllene. Bicyclogermacrene, which had been reported in lime oils by $\mathrm{Tu}$ et al. [9] and Ferhat et al. [31] was found in Jinchen peel oil in minor amounts $(0.01 \%)$, but was not found in Jinchen fruit juice.

It is interesting to note the large difference between the numbers of alcohols and esters found in the fruit juice and peel oil. Six alcohols only found in the fruit juice were 1-octanol, $\beta$-terpineol, terpinen4-ol, nerol, trans-carveol, and geraniol. These have been mentioned as important compounds associated to the pulp in the juice [32]. Another possible reason for their presence is that the alcohols are reaction products generated during the processing or storage of the orange juice. Terpinen-4-ol is the degradation product of D-limonene and linalool during the heat treatment of juice and its concentration significantly increased during the storage of the heat-treated juices [33].

Esters have been described to be most important to orange flavor. Ethyl butanoate followed by ethyl acetate, ethyl propanoate, and methyl butanoate, only present in fruit juice, were not detected in peel oil. These lower boiling points and high volatility esters could have higher degree of affinity in the pulp. Aldehyde content, especially of octanal and decanal, is generally considered one of the standards for characterization for orange peel oil, [2]. These compounds were the most predominant among the aldehyde compounds in both samples, occurring in higher proportions in fruit juice than in peel oil. In addition, other aliphatic aldehydes play an important role in orange flavor [11]. Nonanal, and dodecanal were only present in peel oil, whereas hexanal, trans-2-hexenal, heptanal, undecanal were only detected in fruit juice. A terpenic aldehyde only present in the peel oil was citronellal, constituting $0.06 \%$ of all volatile compounds, which has been reported in many citrus oils $[9,11,13,28]$. The aldehydes are most likely enzymatic degradation products of unsaturated fatty acids such as oleic acid, linoleic acid and linolenic acid [28].

With respect to the rest of the identified components, nootkatone was found in both fruit juice and peel oil. It is a typical component of grapefruits, and its content in the fruits increases with maturation and storage [34]. One terpenic oxide compound (trans-limonene oxide) was identified only in the peel oil of Jinchen fruit. It is possible that the limonene oxidation during the process and storage may be responsible for the formation of this compound in peel oil.

\section{Gas chromatography-/olfactometry (GC-/O) analysis}

It was cosidered very necessary to determine the components responsible for the quality of the aroma of Jinchen fruit, therefore, GC-O was performed for further studying the aromatic profile of Jinchen fruit juice and peel oil.

The odor descriptors for all volatile components perceived by panelists in fruit juice and peel oil extracts of Jinchen fruit are shown in Table 2. As a result of the different odor thresholds of each component, not all of the compounds quantified contribute to the aroma in the juice and peel oil. However, olfactometric analysis utilizes the highly selective detector (human nose) that can detect potent low-level aroma-active compounds which could not be quantified by GC-MS (trans-2-hexen-1ol, ethyl 3-hydroxyhexanoate, and six unknown compounds). 
Table 2. Aroma active compounds of fruit juice and peel oil detected by GC-O.

\begin{tabular}{|c|c|c|c|c|}
\hline \multirow{2}{*}{ Compound name } & \multirow{2}{*}{ RI(HP-5) } & \multirow{2}{*}{ Odor } & \multicolumn{2}{|c|}{ Intensity \pm SD } \\
\hline & & & Fruit juice & Peel oil \\
\hline Hexanal & 794 & Green & $2.3 \pm 0.9$ & n.d. \\
\hline Ethyl butanoate & 795 & Fruity, Apple & $3.8 \pm 0.5$ & n.d. \\
\hline trans-2-Hexenal & 849 & Green & $1.8 \pm 0.4$ & n.d. \\
\hline trans-2-Hexen-1-ol & 869 & Green & $2.6 \pm 0.5$ & n.d. \\
\hline$\alpha$-Pinene & 930 & Piney & $3.3 \pm 0.9$ & $3.6 \pm 0.5$ \\
\hline Camphene & 947 & Camphor & n.d. & $1.0 \pm 0$ \\
\hline$\beta$-pinene & 982 & Piney & $3.5 \pm 0.6$ & n.d. \\
\hline $\mathrm{NI}$ & 984 & Grassy & $3.3 \pm 0.5$ & n.d. \\
\hline$\beta$-Myrcene & 992 & Lemon, Grapefruit, Musty, Spicy & $3.6 \pm 0.8$ & $3.3 \pm 0.5$ \\
\hline Octanal & 1011 & Fruity, Citrusy & $3.8 \pm 0.4$ & $2.9 \pm 0.9^{*}$ \\
\hline Limonene & 1040 & Lemon, Minty, Orange & $2.7 \pm 0.8$ & $2.5 \pm 0.8$ \\
\hline$\gamma$-Terpinene & 1064 & Sweet, Citrusy & n.d. & $1.5 \pm 0.5$ \\
\hline Terpinolene & 1088 & Green & n.d. & $2.0 \pm 0$ \\
\hline Linalool & 1104 & Fruity & $4.0 \pm 0$ & $3.9 \pm 0.4$ \\
\hline Nonanal & 1107 & Piney & n.d. & $1.0 \pm 0.5$ \\
\hline $\begin{array}{l}\text { Ethyl 3-hydroxy- } \\
\text { hexanoate }\end{array}$ & 1138 & Citrusy & $2.6 \pm 1.0$ & n.d. \\
\hline$\beta$-Terpineol & 1146 & Green & $3.3 \pm 0.6$ & n.d. \\
\hline Citronellal & 1156 & Minty & n.d. & $3.0 \pm 0$ \\
\hline NI & 1167 & Camphor, Minty & $2.8 \pm 0.5$ & n.d. \\
\hline NI & 1176 & Green & n.d. & $2.7 \pm 1.0$ \\
\hline Terpinen-4-ol & 1186 & Green & $2.4 \pm 1.0$ & n.d. \\
\hline$\alpha$-Terpineol & 1196 & Lemon, Piney, Minty & $3.5 \pm 0.5$ & $3.3 \pm 1.0$ \\
\hline Decanal & 1206 & Fruity, Soap, Balsamic & $3.7 \pm 0.6$ & $3.6 \pm 0.5$ \\
\hline NI & 1213 & Metal & $2.6 \pm 0.8$ & n.d. \\
\hline trans-Carveol & 1222 & Caraway & $2.6 \pm 0.5$ & n.d. \\
\hline Nerol & 1232 & Lemon & $2.8 \pm 0.4$ & n.d. \\
\hline Neral & 1244 & Rose & $1.3 \pm 0.6$ & n.d. \\
\hline Carvone & 1250 & Caraway & $2.3 \pm 0.5$ & n.d. \\
\hline NI & 1253 & Fruity & n.d. & $2.0 \pm 0$ \\
\hline Geraniol & 1258 & Floral, Lemon, Minty & $2.6 \pm 0.8$ & n.d. \\
\hline NI & 1259 & Floral & n.d. & $2.6 \pm 0.5$ \\
\hline Geranial & 1273 & Floral, Citrusy & $2.0 \pm 0$ & $2.0 \pm 1.0$ \\
\hline Perillaldehyde & 1278 & Green & $2.3 \pm 0.6$ & $2.5 \pm 0.5$ \\
\hline Thymol & 1296 & Metal & $1.0 \pm 0$ & n.d. \\
\hline $\begin{array}{l}\text { trans,trans-2,4- } \\
\text { Decadienal }\end{array}$ & 1323 & Fatty & $3.0 \pm 0$ & $2.2 \pm 0.4^{*}$ \\
\hline$\alpha$-Cubebene & 1352 & Herb & $1.3 \pm 0.5$ & n.d. \\
\hline Geranyl acetate & 1386 & Sweet & $1.2 \pm 0.4$ & n.d. \\
\hline$\beta$-Cubebene & 1397 & Fruity & n.d. & $1.0 \pm 0$ \\
\hline Valencene & 1499 & Citrusy & $2.8 \pm 0.4$ & $1.2 \pm 0.4^{*}$ \\
\hline Bicyclogermacrene & 1500 & Green & n.d. & $2.0 \pm 0$ \\
\hline$\delta$-Amorphene & 1523 & Fruity & $2.0 \pm 0.8$ & $2.3 \pm 1.0$ \\
\hline
\end{tabular}

NI: not identified by GC-MS; n.d.: not detected; * indicates significant difference $(\mathrm{P}<0.05)$ between the fruit juice and peel oil 
A total of 31 components appeared to contribute to the aromatic profile in Jinchen fruit juice. Among them, ethyl butanoate, $\beta$-myrcene, octanal, linalool, and decanal decided the juice aroma because they are the strongest aroma active compounds perceived by all the panelists. Regarding the peel oil, 22 components appeared to contribute to the overall aroma. Linalool, $\alpha$-pinene, and decanal defined the aroma of the oil, because these compounds had the greatest aroma intensity. Twelve compounds were perceived by all the panelists in both juice and oil. Among them, five aromatic compounds present different odor intensity in both samples, such as $\alpha$-pinene, $\beta$-myrcene, octanal, (trans, trans)-2,4-decadienal, and valencene. The intensity of octanal, trans, trans-2, 4- decadienal, and valencene showed the significant difference $(\mathrm{P}<0.05)$ between the fruit juice and peel oil. Especially, valencene exhibited higher intensity in Jinchen fruit juice than in the peel oil, though valencene was not generally considered an important contributor to orange juice flavor in previously reports [20-23].

The different overall aroma between fruit juice and peel oil are attributed to the various composition of aroma active compounds [35]. The components which were perceived by all the panelists and only detected in the fruit juice or peel oil respectively may contribute to the aromatic differences. Among these, 19 components have been perceived only in the juice and 10 compounds were described as aromatic components of only the peel oil by the three panelists. Nineteen volatile components detected by the panelists only in fruit juice contribute to citrusy, green, and piney notes. The other ten volatile components described as aromatic components of only the peel oil impart a camphor, minty, green, fruity, and floral aroma.

According to these results, not all of the components found in greatest concentration by GC-MS contributed to the aroma in orange juice. Limonene was present in highest amount versus other volatiles, but did not exhibit strongest aroma activity though it has orange odor in GC-O of fruit juice and peel oil. In contrast, ethyl 3-hydroxyhexanoate and nerol were not detected by GC-MS and found in low concentration, contributing to citrusy and lemon aroma of the fruit juice according to GC-O intensity data.

Most odorant compounds characterized in Jinchen orange juice were also detected in some sweet orange juice[20-21], such as ethyl butyrate, myrcene, octanal, decanal, terpinen-4-ol, linalool, limonene, $\alpha$-pinene, and hexanal, but nonanal and (E)-2-nonenal was not found to be major aroma active compound in Jinchen juice. There were also some aroma active compounds detected in Jinchen juice not commonly reported in other orange juices, such as ethyl 3-hydroxyhexanoate, perillaldehyde, thymol, trans,trans-2,4-decadienal, $\delta$-amorphene. The aroma activities of these compounds in sweet orange flavor are not well documented. Most volatile compounds detected in Jinchen peel-oil were also found in many citrus oils, such as limonene, $\alpha$-pinene, myrcene, octanal, decanal, terpinen-4-ol, linalool, $\gamma$-terpinene, terpiolene, citronellal, neral, $\alpha$-copaene, valencene and nootkatone. These compounds were previously reported in other citrus oils but their aroma activities and contribution to citrus oil flavor were not described [9-11, 36-39]. $\delta$-Amorphene was the only compound found and identified tentatively in Jinchen peel-oil not previously reported in other citrus essential oils. 


\section{Conclusions}

In conclusion, in this study of the aromatic composition of fruit juice and peel oil of Jinchen orange a total of 57 components identified. GC-O was used to detect the aroma active compounds. There are 31 aromatic compounds present in the fruit juice, and 22 components appear to be the major contributors to the peel oil aroma, respectively. Twelve compounds were perceived by all panelists in juice and peel samples. Five compounds not identified by GC-MS were characterized in both samples. For fruit juice, ethyl butanoate, $\beta$-myrcene, octanal, linalool, and decanal had greatest aroma intensity. Linalool, $\alpha$-pinene, and decanal presented highest aroma intensity in peel oil. Nineteen components have been perceived only in the juice sample, and ten compounds were described as aromatic components of only the peel oil by the panelists. These differences probably lead to the different overall aroma between fruit juice and peel oil. The aromatic composition in the fruit juice was more complex than that of the peel oil.

\section{Experimental}

\section{Fruit juice and peel oil samples}

Unpasteurized Jinchen orange fruit juice and peel oil were obtained from a local manufacturer of citrus products located at Songzi in Hubei province. Both the juice and the peel oil were derived from the same fruit source. The fruit juice was processed with a Polycitrus juice extractor. The peel oil was obtained from cold-pressed peel of the Jinchen orange fruit. The juice and oil samples were stored at $-20{ }^{\circ} \mathrm{C}$ until analyzed.

\section{Extraction of Volatile Compounds}

The manual SPME device equipped with a 50/30 $\mu \mathrm{m}$ DVB/CAR/PDMS fiber (Supelco, Bellfonte, PA, USA) was used for extraction volatile compounds of fruit juice. The fiber was conditioned in the $\mathrm{GC}$ injector port at $270{ }^{\circ} \mathrm{C}$ for $1 \mathrm{~h}$ prior to use. The orange juice $(5 \mathrm{~mL})$ and peel oil $(5 \mathrm{~mL})$ were placed into a $20 \mathrm{~mL}$ vial containing a micro stirring bar, respectively. The sample was equilibrated at $40{ }^{\circ} \mathrm{C} \pm 1{ }^{\circ} \mathrm{C}$ for $15 \mathrm{~min}$ and headspace extracted by DVB/CAR/PDMS fiber for $40 \mathrm{~min}$ at the same temperature under stirring $(500 \mathrm{rpm})$. After extraction, the fiber was inserted into the injection port of the GC to desorb the analytes for $5 \mathrm{~min}$. Each analytical sample was measured in triplicate. The results are reported as the mean values of relative peak area percent \pm SD (standard deviation)

\section{Chemicals}

Authentic standards were obtained as follows: $\alpha$-pinene were purchased from Aldrich Chemical Co. (Germany) $n$-alkanes $\left(\mathrm{C}_{8}-\mathrm{C}_{20}\right)$, ethyl butyrate, $\beta$-myrcene, linalool, decanal, were obtained from FluKa Chemical Co. (Germany). Hexanal, trans-2-hexenal, benzaldehyde, octanal, limonene, nonanal, $\alpha$-terpineol, neral, geranial, neryl acetate, geranyl acetate, citronellyl acetate and valencene were gifts from the GLD-Boton Essential Company (P. R. China). 


\section{GC-MS analysis}

GC-MS was carried out using a HP 5975B quadropole mass selective detector (Agilent Technologies, USA). The Mass spectral ionization temperature was set at $230{ }^{\circ} \mathrm{C}$. The mass spectrometer was operated in the electron impact ionization mode at a voltage of $70 \mathrm{eV}$. Mass spectra were taken over the $m / z$ range $30-400$.

The flow rate of the helium carrier gas on HP-5 column $(30 \mathrm{~m} \times 0.25 \mathrm{mmI} . \mathrm{D}, 0.25 \mu \mathrm{m}$ film thickness, J\&W Scientific, Folsom, CA, USA) was $1 \mathrm{~mL} / \mathrm{min}$. The analysis performed in the splitless mode and injector temperature was $250{ }^{\circ} \mathrm{C}$. The column was held at $40{ }^{\circ} \mathrm{C}$ for $3 \mathrm{~min}$, and then increased from $40{ }^{\circ} \mathrm{C}$ to $160{ }^{\circ} \mathrm{C}$ at $3{ }^{\circ} \mathrm{C} / \mathrm{min}$, held at $160{ }^{\circ} \mathrm{C}$ for $2 \mathrm{~min}$, and finally increased to $220{ }^{\circ} \mathrm{C}$ at a rate of $8{ }^{\circ} \mathrm{C} / \mathrm{min}$, then held for $3 \mathrm{~min}$.

Volatile components were identified by comparing their mass spectra with the mass spectra from MS libraries (NIST 05, WILEY 7.0). When available, MS identifications were confirmed by comparing GC retention times of the analytes with those from pure standards. The identification was confirmed using retention indices (RI), and the value was compared with those reported in the literature. Linear retention indices (RI) of the compounds were calculated using a series of $n$-alkanes $\left(\mathrm{C}_{8}-\mathrm{C}_{20}\right.$, Sigma-Aldrich, Germany) injected in the same conditions. When standard chemicals were not available, tentative identification was carried out by matching the mass spectra. The results are given in Table 1.

\section{GC-Olfactometry}

The analysis was carried out using a HP 6890 GC equipped with a HP-5 column $(30 \mathrm{~m} \times 0.25 \mathrm{~mm}$ I.D, $0.25 \mu \mathrm{m}$ film thickness, J\&W Scientific, Folsom, CA, USA) directly connected to a HP 5975 series mass selective detector and a sniffing port (ODP2, Gerstel,Inc., Baltimore, MD). The GC effluent was split $1 / 2$ between the mass spectrometer and the sniffing port. The transfer line to the GC$\mathrm{O}$ sniffing port was held at $280{ }^{\circ} \mathrm{C}$. The volume of sample extract analyzed and oven program temperatures were the same as those described above for the GC-MS. Humidified air was added in the sniffing port at $60 \mathrm{~mL} / \mathrm{min}$. Compound identifications were made by comparison of the mass spectra, retention times, and the RI of the volatile components in both extracts with those of corresponding reference standards. The mass spectrometer retention times were compared with the retention times measured in the olfactometry runs, and both were compared to reference standards.

Three panelists were used for the intensity detection and verbal description of the odor active components identified in both extracts by GC-O. The first training was familiarization with the scale and the system in a short period. During this period the panelists performed three times analysis of one of the test samples and rate intensity of the eluted odor using the four scale (1=extremely weak, $2=$ clear but not intense odor, $3=$ intense odor, $4=$ extremely strong). They were not instructed about what was the expected intensity of the odors and each one used the intensity category, which in his / her opinion fitted best the intensity of the odor perception caused by the eluted odorant. Test data were recorded only after panelists demonstrated an ability to replicate analyses and the scales given by each panelist were not significant difference. After the successful test, the trained panelists carried out sniffing the samples and recorded the perceived intensities of the odor. 
The results of intensity from two samples were statistically evaluated by one way analysis of variance (ANOVA). Statistically, differences with P-values under 0.05 were considered significant

\section{Acknowledgements}

The authors are grateful for the support given by the Wangchunhua citrus valley Co., Ltd, which supplied the orange juice. This work is supported by the 948 Project of Ministry of Agriculture, China (2006-Z-25).

\section{References and Notes}

1. Dhuique-Mayer; Caris-Veyrat, C.; Ollitrault, P.; Curk, F.; Amiot, M.J. Varietal and interspecific influence on micronutrient contents in citrus from the Mediterranean area. J. Agric. Food Chem. 2005, 53, 2140-2145.

2. Nisperos-Carriedo, M.O; Shaw, P.E. Comparison of volatile flavor components in fresh and processed orange juices. J. Agric. Food Chem. 1990, 38, 1048-1052.

3. Moshonas, M.G.; Shaw, P.E. Quantitative determination of 46 volatile constituents in fresh, unpasteurized orange juices using dynamic headspace gas chromatography. J. Agric. Food Chem. 1994, 42, 1525-1528.

4. Steffen, A.; Pawliszyn, J. Analysis of flavor volatiles using headspace solid-phase microextraction. J. Agric. Food Chem. 1996, 44, 2187-2193.

5. Jia, M.Y.; Zhang, Q.H.; Min, D.B. Optimization of solidphase microextraction analysis for headspace flavor compounds of orange juice. J. Agric. Food Chem. 1998, 46, 2744-2747.

6. Selli, S.; Cabaroglu, T.; Canbas, A. Volatile flavour components of orange juice obtained from the cv. Kozan of Turkey. J. Food Compos. Anal. 2004, 17, 789-796.

7. Jordán, M.J.; Goodner, K.L.; Castillo, M.; Laencina, J. Comparison of two headspace solid phase microextraction fibers for the detection of volatile chemical concentration changes due to industrial processing of orange juice. J. Sci. Food Agric. 2005, 85, 1065-1071.

8. Lota, M.L.; De Rocca Serra, D.; Jacquemond, C.; Tomi, F.; Casanova, J. Chemical variability of peel and leaf essential oils of sour orange. Flavour Fragr. J. 2001, 16, 89-96.

9. Tu, N.T.M.; Thanh, L.X.; Une, A.; Ukeda, H.; Sawamura, M. Volatile constituents of Vietnamese pummelo, orange, tangerine and lime peel oils. Flavour Fragr. J. 2002, 17, 169-174.

10. Mitiku, S.B.; Sawamura, M.; Itoh, T.; Ukeda, H. Volatile components of peel cold-pressed oils of two cultivars of sweet orange (Citrus sinensis (L.) Osbeck) from Ethiopia. Flavour Fragr J. 2000, 15, 240-244.

11. Högnadóttir, Á.; Rouseff, R.L. Identification of aroma active compounds in orange essence oil using gas chromatography -olfacotmetry and gas chromatography-mass spectrometry. $J$. Chromatogr. A. 2003, 998, 201-211.

12. Smadja, J.; Rondeau, P.; Sing, A.S.C. Volatile constituents of five Citrus Petitgrain essential oils from Reunion. Flavour Fragr. J. 2005, 20, 399-402. 
13. Njoroge, S.M.; Koaze, H.; Mwaniki, M.; Tu, N.T.M.; Sawamura, M. Essential oils of Kenyan Citrus fruits: volatile components of two varieties of mandarins (Citrus reticulata) and a tangelo (C. paradisi $\times$ C. tangerina). Flavour Fragr. J. 2005, 20, 74-79.

14. Guth, H.; Grosch, W. In: Flavor Chemistry; Teranishi, R., Wick, E.L., Hornstein, I., Eds; Kluwer Academic:-Plenum: New York, 1999; pp. 377-386.

15. Lin, J.M.; Rouseff, R.L.; Barros, S.; Naim, M. Aroma composition changes in early season grapefruit juice produced from thermal concentration. J. Agric. Food Chem. 2002, 50, 813-819.

16. Fan, W.L.; Qian. M.C. Characterization of aroma compounds of Chinese "Wuliangye" and "Jiannanchun" liquors by aroma extract dilution analysis. J. Agric. Food Chem. 2006, 54, 2695 2704.

17. Guillot, S.; Peytavi, L.; Bureau, S.; Boulanger, R.; Lepoutre, J.P.; Crouzet, J.; Schorr-Galindo, S. Aroma characterization of various apricot varieties using headspace-solid phase microextraction combined with gas chromatography-mass spectrometry and gas chromatography-olfactometry. Food Chem. 2006, 96, 147-155.

18. Ruth, S.M. Methods for gas chromatography-olfactometry: a review. Biomol. Eng. 2001, 17, 121 128.

19. Ruth, S.M.; O'Connor, C.H. Evaluation of two chromatography-olfactometry methods: the detection frequency and perceived intensity method. J. Chromatogr. A. 2004, 1054, 33-37.

20. Bazemore, R.; Goodner, K.L.; Rouseff, R.L. Volatiles from unpasteurized and excessively heated orange juice analyzed with solid phase microextraction and GC-olfactometry. J Food Sci. 1999, 64, 800-803.

21. Tonder, D.; Petersen, M.A.; Poll, L.; Olsen, C.E. Discrimination between freshly made and stored reconstituted orange juice using GC odor profiling and aroma values. Food Chem. 1998, 61, 223229.

22. Rega, B.; Fournier, N.; Guichard, E. Solid phase microextratiocn (SPME) of orange juice flavor: odor representativeness by direct gas chromatography olfactometry (D-GC-O). J. Agric. Food Chem. 2003, 51, 7092-7099.

23. Arena, E.; Guarrera, N.; Campisi, S.; Nicolosi Asmundo, C. Comparison of odour active compounds detected by gas-chromatography-olfactometry between hand-squeezed juices from different orange varieties. Food Chem. 2006, 98, 59-63.

24. Kataoka, H.; Lord, H.L; Pawliszyn, J. Applications of solid phase microextraction in food analysis. J. Chromatogr. A. 2000, 880, 35-62.

25. Yang, X.Y.; Peppard, T. Solid-phase microextraction for flavor analysis. J. Agric. Food Chem. 1994, 42, 1925-1930.

26 Jia, M.; Zhang, Q.H.; Min. D.B. Optimization of solid-phase microextraction analysis for headspace flavor compounds of orange juice. J. Agric. Food Chem. 1998, 46, 2744-3747.

27. Tae, H.K.; Sang, M.L.; Kim, Y.S.; Kim, K.H.; Oh, S.; Lee, H.J. Aroma dilution method using GC injector split ratio for volatile compounds extracted by headspace solid phase microextraction. Food Chem. 2003, 83, 151-158.

28. Lin, J.M.; Rouseff, R.L. Characterization of aroma-impact compounds in cold-pressed grapefruit oil using time-intensity GC-olfactometry and GC-MS. Flavour Fragr. J. 2001, 16, 457-463. 
29 Dharmawan, J.; Kasapis, S; Curran, P.; Johnson, J.R. Characterization of volatile compounds in selected citrus fruits from Asia. Part I: freshly-squeezed juice. Flavour Fragr. J. 2007, 22, 228232.

30. Hamm, S.; Lesellier, E.; Bleton, J.; Tchapla, A. Optimization of headspace solid phase microextraction for gas chromatography/mass spectrometry analysis of widely different volatility and polarity terpenoids in olibanum. J. Chromatogr. A. 2003, 1018, 73-83.

31. Ferhat, M.A.; Meklati, B.Y.; Chemat, F. Comparison of different isolation methods of essential oil from Citrus fruits: cold pressing, hydrodistillation and microwave 'dry' distillation. Flavour Fragr. J. 2007, 22, 494-504.

32. Jordan, M.J.; Tillman, T.N.; Mucci, B.; Laencina, J. Using HS-SPME to determine the effects of reducing insoluble solids on aromatic composition of orange juice. Lebensm. Wiss. Technol. 2001, 34, 244-250.

33. Pérez-López, A.; Saura, D.; Lorente, J.; Carbonell-Barrachina, Á.A. Limonene, linalool, $\alpha-$ terpineol, and terpinen-4-ol as quality control parameters in mandarin juice processing. Eur. Food Res. Technol. 2006, 222, 281-285.

34. Sawamura, M.; Kuwahara, S.; Shichiri, K.; T, Aoki. Volatile constituents of several varieties of pummelos and a comparison of the nootkatone levels in pummelos and other citrus fruits. Agric. Biol. Chem. 1990, 54, 803-805.

35. Jordán, M.J.; Tandon, K.; Shaw, P.E.; Goodner, K.L. Aromatic Profile of Aqueous Banana Essence and Banana Fruit by Gas Chromatography-Mass Spectrometry (GC-MS) and Gas Chromatography-Olfactometry (GC-O). J. Agric. Food Chem. 2001, 49, 4813-4817.

36. Njoroge, S.M.; Koaze, H.; Karanja, P.N.; Sawamura, M. Essential oil constituents of three varieties of Kenyan sweet oranges(Citrus sinensis). Flavour Fragr. J. 2005, 20, 80-85.

37. Song, H.S.; Phi, N.T.L.; Park, Y.H.; Sawamura, M. Volatile profiles in cold-pressed peel oil from Korean and Japanese Shiranui (Citrus unshiu Marcov. x Citrus sinensis Osbeck x Citrus reticulata Blanco). Biosci. Biotechnol. Biochem. 2006, 70, 737-739.

38. Sawamura, M.; Nguyen, T.M.T.; Yu, X.L.; Xu, B.Q. Volatile constituents of the peel oils of several sweet oranges in China. J. Essent. Oil Res. 2005, 17, 2-6.

39. Dharmawan, J.; Kasapis, S.; Curran, P. Characterization of volatile compounds in selected citrus fruits from Asia - Part II: Peel oil. J. Essent. Oil Res. 2008, 20, 20-24.

Sample Availability: Available from the authors.

(C) 2008 by the authors; licensee Molecular Diversity Preservation International, Basel, Switzerland. This article is an open-access article distributed under the terms and conditions of the Creative Commons Attribution license (http://creativecommons.org/licenses/by/3.0/). 